\title{
A composição dos dias de jogos da Arena do Grêmio na vida de moradores e não moradores das imediações do estádio
}

\author{
The Matchdays Composition of the Arena do Grêmio in the \\ Residents and Non-Residents Lives Around the Stadium
}

\author{
Daiane Grillo Martins \\ Instituto de Desenvolvimento, Ensino e Assistência à Saúde, São Leopoldo/RS, Brasil \\ Mestra em Educação Física, UFPEL \\ daia.martins82@gmail.com \\ Alan Goularte Knuth \\ Universidade Federal do Rio Grande, Rio Grande/RS, Brasil \\ Doutor em Epidemiologia, UFPEL
}

\begin{abstract}
REsumo: Nos dias de jogos de futebol, a apropriação dos territórios por torcedores pode se estender para além do interior dos estádios, ocupando suas imediações. Realizamos uma pesquisa etnográfica com o objetivo de compreender a apropriação das imediações da Arena do Grêmio, nos períodos que antecedem os jogos, bem como a descrição de aspectos da vida de moradores e não moradores das imediações do estádio. Consideramos que o território dos dias de jogos na Arena compõe as vidas de moradores das imediações do estádio, de outros bairros de Porto Alegre/RS, cidades e estados. São gremistas, torcedores aliados, guardadores, catadores, comerciantes e demais sujeitos que se relacionam entre si. 0 território é constituído pelas nuances de suas ambiguidades, pela multiplicidade das inter-relações de sociabilidade e pelas relações comerciais, significados e pertencimentos inerentes à apropriação e dominação do espaço, tramadas nas redes da multiterritorialidade.
\end{abstract}

PalaVRAS-Chave: Futebol; Estádio; Torcedores; Moradores; Território.

ABSTRACT: On match days, the appropriation of territories by fans may expand beyond the interior of football stadiums, occupying their surroundings. We conducted an ethnographic research in order to understand the appropriation of the surroundings of the Arena do Grêmio, in the periods before fans' entrance in the stadium, as well as to describe aspects of the lives of residents and non-residents around the stadium. We consider that the territory around the Arena on match days makes up the lives of residents of surroundings, other neighborhoods in Porto Alegre/RS, and nearby cities and states. They are Grêmio supporters, rivals, allies, car watchers, garbage collectors, street traders and other subjects who relate to each other. The territory is constituted in the nuances of its ambiguities, in the multiplicity of interrelationships of sociability and commercial relationships, meanings and belongings inherent to the appropriation and domination of space, woven into multi-territoriality networks.

KEYworDS: Football; Stadium; Fans; Residents; Territory. 


\section{INTRODUÇÃo}

Quando nos propomos a investigar os esportes nos tempos atuais, Gilmar Mascarenhas menciona que estas manifestações compõem "uma dimensão complexa e multifacetada da realidade social, e seu enfrentamento requer o aporte teórico-metodológico das mais diversas disciplinas acadêmicas". Complementa que

os estudos setoriais do fenômeno esportivo não permitem visualizar sua complexidade, mas também porque o estudo da produção da demanda esportiva de determinada sociedade requer uma perspectiva contextual que envolve o espaço geográfico, suas formas e sua dinâmica. ${ }^{1}$

Referindo-nos mais especificamente ao futebol de alto rendimento, essa prática agrega diversificados atores envolvidos na difusão social e também na manutenção dos clubes. Destacamos os públicos torcedores que, segundo Damo, caracterizam-se pelo sentimento de pertencimento clubístico, atribuindo às suas vivências específicos símbolos, linguagens e significados, em que o torcer se estabelece a partir do engajamento emocional, das ligações afetivas de cada sujeito com determinado clube. ${ }^{2}$

Buscando analisar o espaço-tempo vivido das manifestações relativas especificamente aos torcedores e às torcedoras que frequentam estádios de futebol, 3 sinalizamos que essas relações ocorrem não somente dentro destes espaços, mas também podem ocorrer no lado de fora dos estádios, nas suas imediações, nos tempos pré, durante e pós jogo de futebol. Assim, realizamos uma pesquisa de campo com objetivo de compreender como ocorre a apropriação do espaço das imediações da Arena do Grêmio, ${ }^{4}$ situada na zona norte da cidade de Porto Alegre/RS, no período que antecede a entrada dos torcedores no estádio, em dias de jogos. Além disso, buscamos investigar como esse acontecimento compõe a vida dos moradores e das moradoras das imediações do estádio e de outras regiões. ${ }^{5}$

\footnotetext{
${ }^{1}$ MASCARENHAS. À Geografia e os esportes, 1999, p. 57.

2 DAMO. Esporte e sociedade, 2006. DAMO. Do dom à profissão, 2007.

3 HAESBAERT. Território e multiterritorialidade: um debate, 2007.

${ }^{4}$ A fase empírica da pesquisa foi realizada pela primeira autora deste trabalho.

${ }^{5}$ Da pesquisa desdobraram-se dois artigos. Um deles, que trata especificamente da análise da configuração do território, está disponível na Revista Movimento da UFRGS (MARTINS; KNUTH. Manifestações torcedoras e território: configurações das imediações da Arena do
} 


\section{Da Fundação do GrÊMio Foot-Ball Porto AlEgrense À ARENA do GrÊMio no Humaitá}

O Grêmio Foot-Ball Porto Alegrense foi fundado em 15 de setembro de 1903. Em outubro de 1912, o clube inaugurou um pavilhão para 500 pessoas e lá jogou por quase 50 anos. 0 estádio ficou conhecido como Fortim da Baixada. ${ }^{6}$ Ao final da década de 1940, o Grêmio passou por transformações significativas, incluindo a transferência da sede para um novo estádio, construído no Bairro Azenha. 0 estádio Olímpico Monumental foi inaugurado nos primeiros anos da década de 1950 e foi a casa do clube até a fundação, em dezembro de 2012, da Arena do Grêmio, no bairro Humaitá. ${ }^{7}$

O Humaitá situa-se na zona norte de Porto Alegre, a $8 \mathrm{~km}$ do centro da cidade, limitando-se ao sul com o bairro de Navegantes e, ao norte, com o município de Canoas. Em uma área alagadiça que sofreu processo de aterramento, o território teve seus primeiros movimentos de ocupação na década de 1960, através da ampliação das zonas residenciais para atender o crescimento populacional, decorrente da reestruturação oriunda da industrialização na capital gaúcha e do êxodo rural. ${ }^{8}$

Entre os anos de 1996 e 2005, o Humaitá teve aumento significativo da população, devido à expansão das vilas e às invasões ocorrentes a muitos prédios construídos. Já os anos de 2006 a 2009 são marcados pelo domínio imobiliário, denominando o Novo Humaitá, alavancado pelo promissor complexo de entretenimento, situado ao norte do bairro, contemplando em seu projeto original, além da Arena do Grêmio, também um hotel, prédios residenciais, shopping, centro de convenções e empresarial e estacionamento. ${ }^{9}$

No Brasil, os grandes estádios de futebol cumprem papel relevante na reprodução social urbana, onde o calendário futebolístico demarca os tempos e os

Grêmio, 2020). Portanto, este trabalho é dedicado à investigação sobre a composição dos dias de jogos na vida de moradores das imediações do estádio e de outras regiões.

${ }^{6}$ RODRIGUES. Amizade, trago e alento, 2012.

7 DAMO. Futebol e identidade social, 2002.

${ }^{8}$ MARTINS. O Humaitá de ontem, de hoje e de amanhã, 2010; BIANCHI, Agentes e práticas da organização capitalista do espaço, 2012.

${ }^{9}$ MARTINS. O Humaitá de ontem, de hoje e de amanhã, 2010. 
horizontes da vida cotidiana. ${ }^{10}$ Portanto, há de se considerar que a Arena do Grêmio foi inaugurada há oito anos nessa localidade, fato que apontamos como gerador de transformações no Humaitá e bairros próximos. ${ }^{11}$

\section{TRAJETOS TEÓRICO-METODOLÓGICOS}

Para a realização dessa investigação, embasamos na etnografia, entendida como "a arte e a ciência de descrever um grupo humano - suas instituições, seus comportamentos interpessoais, suas produções materiais e suas crenças". ${ }^{12} \mathrm{Na}$ produção do conhecimento etnográfico, "o olhar, o ouvir e o escrever" constituemse etapas indispensáveis à apreensão dos fenômenos sociais. ${ }^{13}$ Ressaltamos ainda que as ações de andar, ver e escrever são três fluxos que dinamicamente se interrelacionam, exercendo e sofrendo influências recíprocas. ${ }^{14}$ Assim, foram realizadas caminhadas, observações, conversas e diários de campo. Também utilizamos, para auxílio das confecções dos diários, imagens fotografadas e filmadas através de smartphone, de uso pessoal.

Considerando aspectos éticos relativos às falas, os nomes dos sujeitos pesquisados são fictícios, já que "a etnografia, como qualquer produção reflexiva, requer uma seleção do que pode e deve ser divulgado". ${ }^{15}$ A pesquisa foi aprovada junto ao Comitê de Ética em Pesquisa (CEP) da Faculdade de Medicina, da Universidade Federal de Pelotas (UFPEL), que emitiu parecer no 2.897.136. No segundo semestre de 2018, de 23 de setembro a 02 de dezembro, ocorreu a imersão no campo, totalizando sete incursões, em dias de jogos oficiais do Grêmio, sendo cinco no Campeonato Brasileiro e dois na Copa Libertadores da América.

A prioridade de espaço-tempo de observação ficou reservada ao período que antecedeu aos jogos, na extensão da Avenida Padre Leopoldo Brentano,

\footnotetext{
${ }^{10}$ MASCARENHAS. Construindo a pátria de chuteiras, 1998; MASCARENHAS. A Geografia e os esportes, 1999.

${ }^{11}$ Salientamos que até o ano de 2016, a Arena do Grêmio situou-se no bairro Humaitá. No entanto, através da mudança no plano diretor de Porto Alegre, o estádio passou a ser localizado no bairro Farrapos.

${ }^{12}$ ANGROSINO. Etnografia e observação participante, 2009, p. 30.

13 OLIVEIRA. O trabalho do antropólogo, 2006, p. 18.

14 SILVA. A situação etnográfica: andar e ver, 2009.

${ }^{15}$ GOMES; MENEZES. Etnografias possíveis: "estar" ou "ser" de dentro, 2008, p. 3.
} 
tendo início no Bar do Tricolor, até o Bar do Ito, na Avenida AJ Renner. Destacamos que as imediações da Arena contemplam um espaço além do território da pesquisa. No entanto, foi preciso, já nas primeiras idas ao campo, delimitar o espaço de investigação.

Então, além de um recorte temporal, também houve um recorte espacial, que se deu por meio da possibilidade de ver o campo, ${ }^{16}$ considerando dois aspectos específicos: o cenário de permanência de maior número de torcedores e demais sujeitos do campo e também por proporcionar maior sensação de segurança à pesquisadora que circulava sozinha nesses espaços. 0 território em que houve a imersão pode ser visualizado através das seguintes imagens de satélite, as quais apontam a rota percorrida e suas extremidades, sinalizadas pelas setas, na imagem de satélite (Fig. 1).

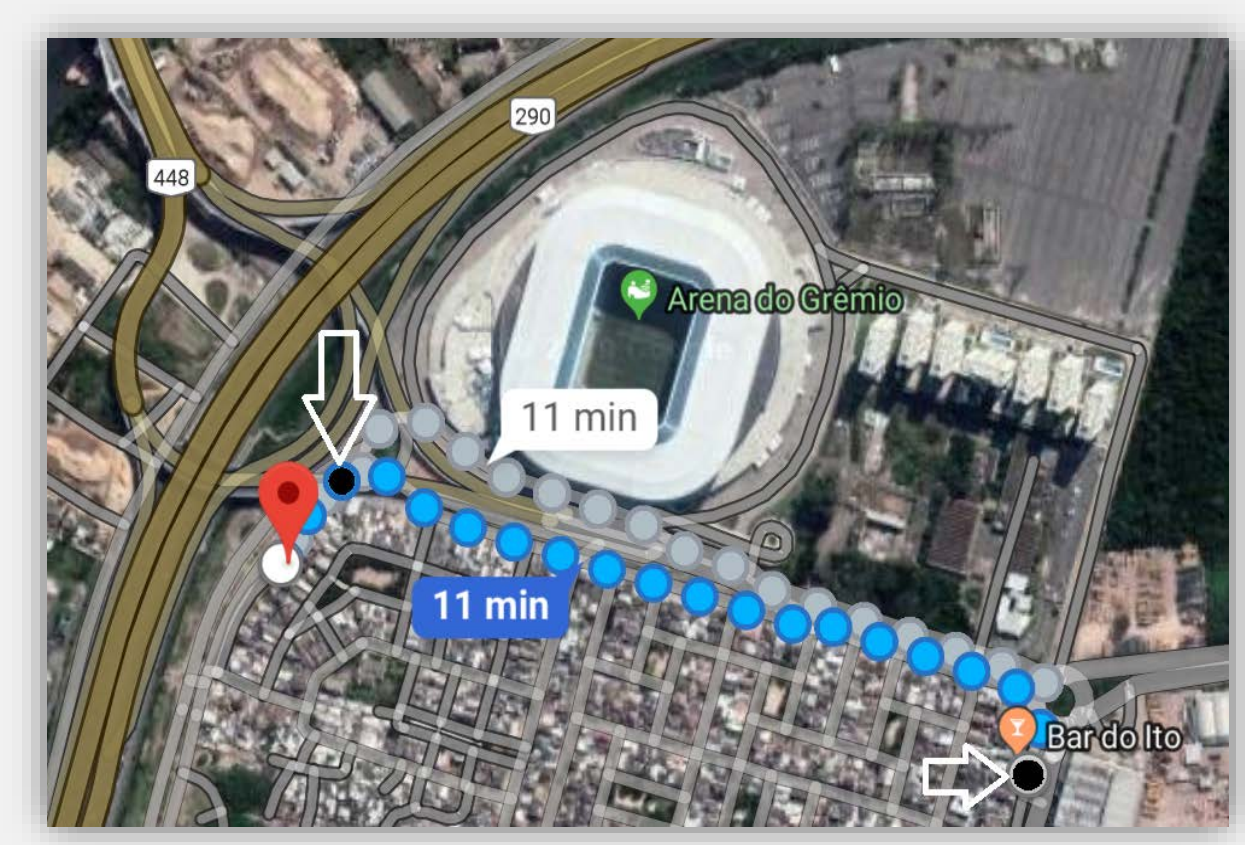

Fig. 1: Rota do campo de pesquisa. Fonte: Google Maps, 2019.

\footnotetext{
${ }^{16}$ Ocorre que ver, sendo diferente de olhar pura e simplesmente, implica uma organização do que foi olhado, espiado, espionado, entrevisto, reparado, notado, percebido ao longo do percurso etnográfico. Ver implica um olhar que se organiza; um olhar organizado e reorganizado; que vai organizando; que organiza e reorganiza; que vai revendo; que revê e dá por revisto (SILVA, 2009, p. 181 e 182).
} 
Dependendo dos acontecimentos durante o processo de pesquisa, o tempo estimado de permanência a cada imersão teve variações de uma a quatro horas. ${ }^{17}$ Em um dia de Libertadores, houve também a necessidade de permanecer em campo durante o período do jogo, mesmo que a previsão projetada contemplasse, preferencialmente, o período pré-jogo. Isso porque, por tratar-se de pesquisa qualitativa, o cientista social tem como preocupação básica “a estreita aproximação dos dados, de fazê-lo falar de forma mais completa possível, abrindo-se à realidade social para melhor apreendê-la e compreendê-la".18

\section{A PULSAÇÃO DOS DIAS DE JOGOS COMO COMPONENTE DE VIDAS}

Ao tratar de territorialização em tempos atuais, especificamente nos ambientes urbanos, Haesbaert nos direciona ao entendimento de multiterritorialidade, caracterizada pela multiplicidade de territórios que não é isolada, mas que se estabelece em redes.

É, assim, antes de tudo, a forma dominante, contemporânea ou 'pósmoderna' da reterritorialização [...] é consequência direta da predominância, especialmente no capitalismo pós-fordista ou de acumulação flexível, de relações sociais construídas através de territóriosrede, sobrepostos e descontínuos, e não mais de territórios-zona [...] o que não quer dizer, em hipótese alguma, que essas formas mais antigas de território não continuem presentes, formando um amálgama complexo com as novas modalidades de organização territorial. ${ }^{19}$

No campo investigado, podemos compreender que a inter-relação dia de jogo na Arena e moradores está para além dos sujeitos que residem nas imediações do estádio. 0 dia de jogo compõe também a vida de moradores de bairros próximos, de outras regiões de Porto Alegre, do interior do Rio Grande do Sul e de

${ }^{17} \mathrm{O}$ deslocamento da pesquisadora, por ser moradora do interior do estado, em quatro idas a campo, ocorreu através de excursão com grupo de torcedores gremistas, da cidade de Rio Grande/RS, os Borrachos do Trovão. Assim, as variações de permanência no campo dependiam do horário de chegada do ônibus às imediações da Arena, que de acordo com as condições da estrada e relevância da partida, chegava de duas a quatro horas antes do horário do jogo. Três idas ocorreram através de ônibus intermunicipal e aplicativo, pois já havia chegado à capital no dia anterior. Esse deslocamento antecipado ocorreu pra que nesses dias, a pesquisadora pudesse chegar mais cedo, visando observar as movimentações iniciais dos sujeitos no território.

${ }^{18}$ MARTINS. Metodologia qualitativa de pesquisa, 2004, p. 292.

${ }^{19}$ HAESBAERT. O mito da desterritorialização, 2010, p. 338. 
outros estados, tramando redes de multiterritorialidade. Mais do que o fim dos territórios, Haesbaert afirma que não há indivíduo ou grupo social sem território, "sem relação de dominação e/ou apropriação do espaço, seja ela de caráter predominantemente material ou simbólico". ${ }^{20}$ Assim, dedicamos a análise aos sujeitos pertinentes ao território, que ali residem e também aos que são moradores de outras localidades.

\section{MORADORES DAS IMEDIAÇõES DA ARENA 21}

Quanto à composição na vida dos moradores das imediações da Arena, referimonos aos sujeitos que possuem residência fixa no território de limitado na investigação. Como foi observado, ao longo dos dias de jogos e, de forma mais intensa em ocasiões que movimentam maior público, grande parte dos lares da avenida interagem com a transformação ocorrente, fazendo parte ativamente desse acontecimento. Essa verificação consta no trecho do diário de campo II:

muitas casas abriam as suas portas para se transformar em comercio de bebidas e lanches. Garagens se transformaram em lancherias, canteiros em centros de comércio de churrasquinho, cachorro quente, entrevero, bebidas e artigos que se remetiam ao clube (bonés, camisas, bandeiras, cavalinhos) [...] ao longo da caminhada, me impressiono com a quantidade de bares, mercearias e lancherias existentes, em que a grande maioria faz alusão ao Grêmio, seja no nome e/ou nas cores do estabelecimento. Do meio para o final da avenida também chamou atenção a quantidade de casas que se transformam em estacionamentos: são calçadas, garagens, pátios guardados por mulheres e homens fixados no centro da rua, chamando por seus clientes que chegam nos seus veículos. ${ }^{22}$

A preparação para a recepção dos torcedores inicia-se horas antes da partida. 0 público começa a chegar cedo, em particular, as excursões, como a dos Borrachos do Trovão, já que estar no território no período pré-jogo faz parte do ritual do grupo de torcedores da cidade de Rio Grande, interior do Rio Grande do Sul, localizada a mais de $300 \mathrm{~km}$ da capital. No diário de campo V, a pesquisadora

\footnotetext{
${ }^{20}$ HAESBAERT. O mito da desterritorialização, 2010, p. 339.

${ }^{21}$ Considerando a mudança recente de localização do território investigado, do Humaitá para Farrapos, por questões empíricas e históricas da popularização do estádio como "Arena do Humaitá", nesta pesquisa, contemplamos como "moradores/as das imediações da Arena" tanto os/as moradores/as do Humaitá, quanto os/as do bairro Farrapos.

22 DIÁRIO DE CAMPO II, 02 out. 2018.
} 
comenta que chegou "na Padre Brentano às 13:50 [...] havia pouca circulação de torcedores, considerando os dias de jogos anteriores e alguns ambulantes já estavam presentes. Os bares e lancherias estavam se preparando. O D' Julia estava abastecendo as bebidas”. ${ }^{23}$ O D' Julia é um ponto comercial, em que há concentração de torcedores também no período do jogo, para assistir a partida televisionada. Em uma das idas a campo, uma das funcionárias relata que a abertura do bar ocorre somente em dias de jogos.

Nesse contexto, em que estabelecimentos comerciais atendem ao público somente em dias de jogos, sendo parte deles o próprio local de moradia dos comerciantes, observamos que o privado também se torna público. Isso ocorre quando os moradores abrem as portas de suas casas para torná-las estabelecimentos de fonte de renda. Assim, muitos torcedores permanecem ao lado de fora do estádio, durante o jogo, assistindo a partida pela transmissão televisiva nos bares e lanchonetes.

O consumo se efetiva no território e as relações de sociabilidade também, principalmente pelo churrasco e a cerveja. A simbologia significativa da bebida compõe a inter-relação entre comerciantes e torcedores. Por isso, a existência do grande número de bares e lanchonetes que tomam conta da extensão do território, incluindo garagens, pátios e calçadas, especificamente para os dias de jogos.

Confraternizar com comida e bebida é um ato coletivo de pertencimento ao território e ao clube. "O clube do coração faz parte disso. Em determinado momento é ele que dá identidade, é ele que faz ser parte de um grupo, é ele que dá rosto. É ele que faz estar junto das pessoas que comungam da mesma visão, dos mesmos sentimentos". 24

Mascarenhas sinaliza que a prática esportiva

implica transformações significativas na forma e na dinâmica territoriais. Primeiramente, o esporte deve ser encarado como uma atividade econômica, particularmente quando realizado em caráter oficial, de competição, e oferecido à sociedade (público espectador) como um artigo de consumo. Enquanto atividade econômica voltada para o entretenimento comercializado, o esporte precisa ser oferecido em lugares apropriados. São estádios, ginásios, pistas diversas, enfim, um

\footnotetext{
23 DIÁRIO DE CAMPO V, 11 nov. 2018.

24 SILVA. Futebol, cultura e sociedade, 2005, p. 50.
} 
amplo conjunto de equipamentos fixos na paisagem e geralmente de grande porte físico, o que resulta em maior capacidade de permanência. ${ }^{25}$

Na mesma perspectiva, Toledo aponta que "no universo do consumo ganha cada vez mais a importância a figura do torcedor consumidor como arrimo moral e legal da ordem esportiva distributiva da riqueza que aí se produz e acumula". ${ }^{26}$ Procurando ampliar o olhar, propomo-nos a dizer que no contexto investigado o comércio/consumo futebolístico está para além do lado de dentro do estádio e dos cofres do clube. Os sujeitos envolvidos no consumo dos dias de jogos também se expandem para o território do entorno do estádio.

Nas imediações da Arena do Grêmio, os dias de jogos constituem composição relevante à vida de moradores, no que tange ao aspecto financeiro. Essa sinalização é proporcionada pelas relações comerciais observadas e reforçada pela conversa com um morador da Avenida Padre Brentano:

Odone [...] conta que é morador antes mesmo da construção da Arena e que a presença do estádio, enquanto seu vizinho, mudou sua vida, já que afirma: "virei empresário". Utiliza seu pátio como estacionamento e construiu um espaço em cima da sua casa, destinado para torcedores/as confraternizar. Além disso, possui uma carrocinha que vende lanches e bebidas. Aponta para sua filha, que trabalha na carrocinha [...] ao falar de seu estabelecimento, Odone relata que ainda não está dentro da regularidade, mas que em breve estará, pois está "batalhando alvará e bombeiros" [...] pergunto quais são os fatores que influenciam no seu lucro e ele afirma que a competição que o Grêmio está disputando é muito importante porque tem relação com a quantidade de público. Menciona que "no campeonato gaúcho a gente ganha bem pouquinho", ate porque "o visitante põe preço", como existem bastantes estacionamentos e pouca clientela, "vira leilão". ${ }^{27}$

Portanto, comercializam-se também os espaços físicos. Odone comercializa o espaço privado de sua residência, tornando negócio o pátio de sua casa e construindo ali um espaço de convivência para locação aos torcedores. 0 empreendedor transforma o que era exclusivamente o seu lar, antes da efetivação da Arena no Humaitá, em lugar de manifestações torcedoras, colocando público e privado em certa relação de simbiose. Seu lar é também a

\footnotetext{
${ }^{25}$ MASCARENHAS. À Geografia dos esportes, p. 7.

${ }^{26}$ TOLEDO. Quase lá: a Copa do Mundo no Itaquerão e os impactos de um megaevento na socialidade torcedora, 2013, p. 152.

${ }^{27}$ DIÁRIO DE CAMPO IV, 03 out. 2018.
} 
sua empresa. Odone é um morador/empresário do território, na inter-relação morador/torcedores/dias de jogos.

Uma situação relevante para se compreender o olhar de torcedores sobre o que os dias de jogos na Arena significam para moradores do território, se deu por meio de uma conversa com dois frequentadores do Bar do Tricolor, pois "quando indagado se achavam que os dias de jogos são importantes para os moradores, Jardel exclama que 'a chegada da Arena foi uma dádiva divina para eles'”. 280 outro torcedor concorda com Jardel. Destacamos ainda que ambos residem em outras áreas de Porto Alegre e frequentam o território exclusivamente em dias de jogos.

A fala de Jardel denota que, ao seu olhar enquanto sujeito torcedor, a presença da Arena e toda configuração pertinente aos dias de jogos possuem função positiva na composição da vida dos moradores das imediações do estádio, o que corrobora a fala de Odone, ao afirmar que a instauração da Arena próxima à sua casa, mudou sua vida. No entanto, após o diálogo com os dois torcedores do Bar do tricolor, um acontecimento proporcionou o entendimento de que nem toda relação dos moradores com os dias de jogos é costurada pela linha da harmonia:

sigo pela Leopoldo Brentano e outra situação chama atenção, que é a fisionomia nada festiva de uma moradora. Estava parada, em frente à sua casa, de braços cruzados, acompanhada de dois senhores, observando o movimento típico dos dias de jogos. Ao passar adiante, resolvo retornar, me apresentar e estabelecer diálogo, pois senti que aquela interação poderia ser importante. $\mathrm{Na}$ rápida conversa que tivemos, dona Nena fez questão de explanar seu incômodo com o movimento dos dias de jogos. Quando perguntei o que significava os dias de jogos para ela, prontamente respondeu "para mim significa bagunça. É um incômodo", corroborando o descontentamento visível em sua fisionomia. Indaguei se ela torcia para algum time e ela responde, elaborando também uma justificativa: "para o Inter, mas meu marido é gremista", apontando prontamente para seu esposo, Jonas. E complementou "mas ele não vai aos jogos". E ele confirma mencionando que nunca foi. A moradora ainda comenta que antes eles ainda ganhavam um dinheiro, fazendo estacionamento na frente da sua casa, mas que agora foi proibido, então eles não têm nenhuma vantagem. ${ }^{29}$

A partir da conversa com os moradores e a moradora, especialmente a que a pesquisadora teve com dona Nena e Jonas, entendemos que se estabelece também

${ }^{28}$ DIÁRIO DE CAMPO III, 06 out. 2018.

${ }^{29}$ DIÁRIO DE CAMPO III, 06 out. 2018. 
a inter-relação entre o dia de jogo e os sujeitos moradores das imediações da Arena, nos aspectos tanto físico (arquitetônico e geográfico), socioeconômico e também de sociabilidade e identidades. Relações estas que são impostas pelo acontecimento da Arena do Grêmio no território, pois se estabelecem através do "controle limitado", em que nossas escolhas nem sempre são produtos de decisões conscientes. Portanto, "há muitas situações equivalentes, nas quais nossa liberdade para agir é limitada por circunstâncias sobre as quais não temos controle". ${ }^{30}$ Logo, a inter-relação se estabelece pelo dia de jogo, proporcionada pela existência do estádio Arena e de moradores em suas imediações.

Aqui também é chamada atenção para a questão de que, além do sentimento de pertencimento ao Grêmio, também podemos nos deparar com a situação inversa: de torcedores de outros clubes que compartilham a vida pulsante do território, em dias de jogos, mas que não compartilham o sentimento de pertencimento a este clube. Levando em consideração que "com relação às práticas cotidianas de liberdade, somos ao mesmo tempo autorizados e constrangidos",31 nos propomos a dizer que provavelmente, assim como dona Nena, também existam outros moradores torcedores do clube rival e de outros clubes, que se sintam constrangidos pela festividade gremista no território.

Expomos ainda que as relações de pertencimento não são apenas do torcedor com o clube, mas também inerente ao contexto socioespacial em que o estádio se localiza. Se o estádio do Grêmio se situa em determinado contexto urbano, os sujeitos que lá habitam, em suas moradias e/ou ambiente de trabalho, de alguma forma, têm seus modos de vida compostos à vida pulsante do clube e da circulação de torcedores gremistas em dias de jogos. Assim como os torcedores, ao ter o estádio de seu clube situado em determinado território, também se relacionam e se apropriam desse território, exercendo sua liberdade de permanecer nas imediações do estádio, no período que antecede os jogos.

Como, "para sermos capazes de agir livremente, precisamos ter mais do que livre-arbítrio", 32 as tensões dos pertencimentos e das apropriações denotam

\footnotetext{
${ }^{30}$ BAUMAN; MAY. Aprendendo a pensar com a Sociologia, 2010, p. 34-5.

${ }^{31}$ BAUMAN; MAY. Aprendendo a pensar com a Sociologia, 2010, p. 37.

32 BAUMAN; MAY. Aprendendo a pensar com a Sociologia, 2010, p. 36.
} 
ambiguidades do território. Logo, ser morador das imediações da Arena pode significar a dádiva para alguns e incômodo para outros.

\section{MORADORES/AS DE BAIRROS PRóXIMOS À ARENA E DE OUTRAS LOCALIDADES DE PORTO ALEGRE}

As atividades comerciais também são exploradas por moradores de bairros próximos ao território investigado e de outras localidades de Porto Alegre. Em conversa com um guardador de veículos, que atua na via pública contínua à $\mathrm{AJ}$ Renner, ${ }^{33}$ Edilson conta que os guardadores moram no Humaitá ou em outros bairros das redondezas. Esse relato reforça a inter-relação de geração de renda entre os dias de jogos e moradores das imediações do estádio e também de bairros próximos. No caso dos guardadores, a comercialização é do próprio espaço público da rua:

0 guardador conta que chegou às $7 \mathrm{~h}$ da manhã [...] trabalha nesta função desde o princípio dos jogos na Arena. [...] Indaguei onde estavam os colegas, que pouco mais de uma hora atrás estavam ali, mas agora eu já não via mais nenhum. Ele conta que "vão tudo para casa almoçar. Moram tudo na volta". A conversa flui até que chega seu último cliente, que o guardador acomoda na vaga de seu carro que estava estacionado. Edilson diz que está indo para casa também fazer uma refeição, já que está desde cedo trabalhando, sem comer, sinalizando nossa despedida. ${ }^{34}$

Também foi possível constatar a inter-relação de geração de renda com outros sujeitos do território, que são os catadores. Na quarta ida a campo, houve uma conversa com três catadores, um que se identifica como morador do Humaitá e os demais, moradores de bairros próximos. Dona Vitória, uma encantadora senhora que gosta de uma boa conversa, relata que vai a todos os jogos e cata latinhas porque ajuda na renda familiar, mas, sobretudo, porque o médico indicou que ela fizesse caminhadas. Daí “ela já aproveita a caminhada para 'fazer um dinheirinho'. A catadora de 76 anos comenta que vai coletando o que encontra e os comerciantes também guardam para ela. Caminha até onde dá, mas não chega até o final da avenida”. 35

Para dona Vitória que mora num bairro próximo à Arena e deixou a zona rural para viver na capital, o território, além de ser um lugar de atividade para

\footnotetext{
${ }^{33}$ Local onde parte das excursões de torcedores estacionam os ônibus e pagam o valor cobrado pelos guardadores, para que possam fazer uso do espaço.

${ }^{34}$ DIÁRIO DE CAMPO VII, 02 dez. 2018.

${ }^{35}$ DIÁRIO DE CAMPO VI, 18 nov. 2018.
} 
complementação de renda é também lugar de sociabilidade com os moradores e também com os torcedores, já que "menciona que é bem conhecida por ali, não só pelos moradores que lhe fazem doações, mas também pelos torcedores, que pedem para tirar foto com ela". 36

Dona Vitória também faz parte da festa e embora nunca tenha entrado na Arena, a sua aproximação espacial com o clube ao qual é torcedora se dá pelo lado de fora do estádio, ou seja, o lado de dentro da celebração dos dias de jogos. Ela estabelece relações com os torcedores através da sociabilidade, do sentimento de pertencimento e do trabalho de catar latinhas. Usa camisa e boné do clube, oferece conversa e abraços, pousa para fotos. Portanto, o consumo que os torcedores fazem das bebidas também se relacionam com a catadora, ao gerar fonte de renda. Há relações de solidariedade com os comerciantes locais, que juntam as latas em seus estabelecimentos para doá-las à catadora. Vitória também exerce função de comerciante, pois "tem uma sobrinha que mora próxima à Arena e diz que em dia de jogo vem para ajudá-la, já que é mais uma moradora que faz de sua casa um ponto de comercio, em dias de jogos". ${ }^{37}$

Ainda sobre catadores, endossamos as inter-relações de trabalho informal dos moradores, contemplando Lupicínio, de 34 anos, morador do Planalto, bairro vizinho e Renato, 41 anos, morador do Humaitá:

Portando sacos grandes e cheios, diferente de dona Vitória com sua sacolinha com meia dúzia de latinhas [...], ambos comentam que coletam latas nas imediações da Arena em todos os jogos, desde a fundação do estádio para complementar a renda [...] Ao perguntar sobre a renda aos dois catadores, eles informam que conseguem levantar uma boa quantia por mês, principalmente quando o Grêmio joga "com times maiores" porque tem mais público e quanto mais público, maior o faturamento. Citam que quando o Grêmio perde, esse faturamento também diminui, já que chegam para a coleta antes do jogo e permanecem até o público começar a ir embora das imediações da Arena. Lupicínio conta que no último jogo da Libertadores levou seu material coletado para venda e lucrou 130 reais. Depois voltou novamente ao território para catar mais latinhas e faturou mais 80 reais. 0 que ele considera uma quantia bastante expressiva para um único dia de coleta. ${ }^{38}$

\footnotetext{
${ }^{36}$ DIÁRIO DE CAMPO VI, 18 nov. 2018.

37 DIÁRIO DE CAMPO VI, 18 nov. 2018.

38 DIÁRIO DE CAMPO VI, 18 nov. 2018.
} 
A conversa com os catadores reforça a inter-relação existente entre quem exerce atividade coletora das latinhas por moradores das imediações da Arena, de bairros próximos e a existência do estádio, já que Lupicínio e Renato realizam esse trabalho em todos os jogos, desde o primeiro ocorrido no estádio. Dependendo do status do adversário no universo futebolístico, maior é a quantidade de público, assim como a relevância de uma competição internacional também demanda maior público de torcedores e por isso, movimenta mais geração de renda. Quanto mais público, mais consumo de bebidas. Outra inter-relação do lucro dos catadores é o fator derrota ou vitória do Grêmio. Isso aponta que como, a atividade dos catadores acontece também depois do jogo, o estado de euforia com a vitória faz com que a celebração se estenda no território. Logo, jogo com vitória é comemorado com mais cerveja.

Gonçalves afirma que, em se tratando de mercado, o principal elemento determinante do ritmo de trabalho de catadores é ter quem compre o que foi recolhido. ${ }^{39}$ Assim, complementamos que as inter-relações extravasam os territórios aqui tratados, nas redes da multiterritorialidade. Isso porque existem indivíduos que, mesmo não marcando presença no território dos dias de jogos, também estão envolvidos de alguma forma, o que é o caso dos compradores de latinhas.

Tratando agora das inter-relações pertinentes à configuração do território, compondo vidas de moradores de outras localidades de Porto Alegre, consideramos que estas também não se dão exclusivamente aos sujeitos torcedores. Policiais/fiscais, cambistas, ambulantes podem ser moradores de outras localidades. É o caso de Maria Madalena, ambulante desde o estádio Olímpico e que também exerce o mesmo trabalho nas imediações do estádio Beira Rio, do Sport Club Internacional.

É aposentada e trabalha como ambulante para complementar a renda. Salienta que a renda de ambulante ajuda bastante. Menciona que sempre ocupa o mesmo lugar e que demarca seu espaço com cordas. Porém, "quando é jogo grande, são proibidos de colocar corda" [...]. Pergunto se nos dias de chuva ela também permanece ali. Responde que sim, usando capa de chuva. Todos os jogos do Grêmio ela esta lá, no mesmo lugar. Moradora da zona sul da capital, Maria Madalena se locomove até as imediações da Arena de carro, chegando por volta de

${ }^{39}$ GONÇALVES. O Trabalho no Lixo, 2006. 
cinco horas antes do início jogo e permanecendo por volta de uma hora e meia, após o término da partida. Reforça que "se o jogo é grande, chega mais cedo ainda". Chega à sua casa aproximadamente quatro horas depois que o jogo acaba. ${ }^{40}$

Consideramos que mesmo que o dia de jogo na Arena não faça parte da vida diária dos moradores de Porto Alegre, ele faz parte da estrutura, da organização de vidas, das relações urbanas estabelecidas, em que os dias de jogos possuem uma lógica diferenciada dos dias que não tem jogos. Moradores, torcedores, comerciantes, trabalhadores do transporte e segurança pública organizam suas vidas contemplando também os dias de jogos. Existe transporte público específico exclusivamente para esses dias.

Policiamento e fiscais elaboram e efetivam estratégias de segurança, em função do dia de jogo. Moradores se transformam em empresários. Catadores e guardadores complementam suas rendas em função dos dias de jogos. Torcedores saem mais cedo do trabalho, preparam-se, chegam antecipadamente ao início da partida, para celebrar e confraternizar. 0 dia de jogo na Arena não abre parênteses na vida de moradores da capital gaúcha, já que contextualiza processos que estruturam a lógica da cidade. Logo, o dia de jogo também faz parte da composição de vidas porto-alegrenses.

\section{MORADORES/AS DE OUTRAS CIDADES E ESTADOS}

No que tange aos torcedores e torcedoras, o dia de jogo faz parte da composição de vidas não somente dos que residem em Porto Alegre, mas também de moradores de outras cidades do Rio Grande do Sul, que têm estabelecidas na celebração do dia de jogo, as suas redes de sociabilidade. Redes estas que também se conectam na multiterritorialidade. São torcedores vindos de outros estados e do interior do Rio Grande do Sul, como é o caso dos membros da excursão dos Borrachos do Trovão, que são moradores da zona sul do estado. Nesse contexto, os torcedores organizam seu itinerário para chegar mais cedo e se fixarem, prioritariamente, no Bar do Ito.

Estar nas imediações da Arena, em dias de jogos, faz parte dos espaçostempos vividos das pessoas que lá estão. Como já explanamos, o trabalho de sujeitos

${ }^{40}$ DIÁRIO DE CAMPO V, 11 nov. 2018. 
é tecido neste território, ou ainda, adaptado por torcedores, pela importância dada ao dia e jogo. Integrantes do Borrachos do Trovão comentam que trocam horários de trabalho e dias de folga para que possam comparecer aos jogos do Grêmio. Portanto, a festa não se opõe ao trabalho e não escapa à realidade. Ela faz parte da vida dos sujeitos do território e está inter-relacionada às relações de trabalho. Pessoas trabalham na festa e reorganizam seus dias de trabalho para estar na festa, ser parte da festa. Arranjam suas vidas, fazendo o dia de jogo parte delas.

Desde a primeira viagem junto ao grupo dos Borrachos, a pesquisadora teve oportunidade de vivenciar as longas horas de viagem, com partida de Rio Grande no início da tarde, para os jogos realizados à noite, ou ainda na madrugada chuvosa, em dia de jogo ocorrido pela manhã. Constatou que o hábito de deixar a cidade onde moram, em dia de jogo no meio da semana, chegando às suas casas pouco antes do horário de sair para trabalhar, são acontecimentos pertinentes às vidas de moradores do interior, que torcem por um clube da capital.

Silva atenta que o sentimento de sacrifício está presente no torcer. Faz parte da individuação por meio do futebol que o torcedor resolva "viver seu torcer intensamente e viajar inúmeros quilômetros para assistir a um jogo que será televisionado", ou ainda, gastar "o dinheiro que lhes faz falta para outras coisas com ingressos, com a compra de objetos que lembram seu time, com deslocamento para outras cidades e estádios, justamente porque acreditam que a sua presença será importante para o bom desempenho do time". 41

Portanto, na vida dos sujeitos do campo investigado, o tempo que antecede o jogo está para além do dia de jogo. Ele é pensado e estruturado de forma constante, na tríade espaço-tempo-vida. Nesse contexto,

deve-se começar pensando na estrutura do todo para se compreender a forma das partes individuais. Esses e muitos outros fenômenos têm uma coisa em comum, por mais diferentes que sejam em todos os outros aspectos: para compreendê-los, é necessário desistir de pensar em termos de substâncias isoladas únicas e começar a pensar em termos de relações e funções. E nosso pensamento só fica plenamente instrumentado para compreender nossa experiência social depois de fazermos essa troca. ${ }^{42}$

\footnotetext{
${ }^{41}$ SILVA. Futebol, cultura e sociedade, 2005, p. 27.

42 ELIAS. O processo civilizador, 1994, p. 22.
} 
O espaço-tempo vivido dos dias de jogos na Arena é de festa, é de trabalho, é de lógica específica, mas é também de lógica inerente à vida dos moradores da capital e do interior. Não se abre parênteses. 0 dia de jogo é dia de festejo, mas um festejo que é parte do total da vida das pessoas e, por isso, está inter-relacionada com as demais esferas. Pessoas possuem suas vidas organizadas, incluindo nelas o dia do jogo.

Assim, "o fenômeno humano é dinâmico e uma das formas de revelação desse dinamismo está, exatamente, na transformação qualitativa e quantitativa do espaço habitado". ${ }^{43}$ E nas habitações das imediações da Arena, em dias de jogos, no que tange aos torcedores, não são somente os gremistas que estabelecem relações e apropriações do território. São também os torcedores de times aliados às torcidas do Grêmio, caso da torcida do Club de Regatas Vasco da Gama.

$\mathrm{Na}$ tarde de jogo contra o time do Rio de Janeiro, a pesquisadora chegando à Avenida Padre Brentano se surpreende, ao ver um grupo de torcedores identificados com a camisa do Vasco, que transitavam, vagarosamente, com seus copos de cerveja pelo território. A surpresa ocorreu porque era a primeira vez que presenciava torcedores adversários circulando. Essa descoberta se tratava da aliança existente entre torcidas organizadas do Grêmio e de clubes de outros estados.

Segui rumo à Avenida, na mesma direção a que se dirigiram os torcedores do Vasco. Deparei-me com um grupo ainda maior junto aos torcedores gremistas no Buteco 1903. Aproveitei a oportunidade para abordar dois deles para uma conversa. Apresentei-me e comecei a indagar sobre a aliança das torcidas. Eles contam que as duas torcidas presentes são a Caravela Vascaína e Vasco Maçaramduba, ambas de Santa Catarina, contando com mais de 100 integrantes, vindos de ônibus, nesse dia [...] Os vascaínos explicam que esse tipo de aliança acontece também com torcidas de clubes de outros estados e que a disputa se restringe somente ao interior do estádio, na hora do jogo. Depois que a partida termina, independente do resultado, a confraternização segue do lado de fora do estádio. ${ }^{44}$

Sobre as alianças entre torcidas, Souza elucida que "a partir da década de 1990, o futebol brasileiro foi inserido no rol dos espetáculos midiáticos mais importantes - do ponto de vista da audiência televisiva e atração de investidores privados". Isso estimulou "clubes e jogadores a adequarem-se cada vez mais rápido

43 SANTOS. Metamorfoses do espaço habitado, fundamentos teórico e metodológico da geografia, 1988, p.14.

${ }^{44}$ DIÁRIO DE CAMPO V, 11 nov. 2018. 
aos padrões exigidos pelos interesses do capital". Consequentemente, todos os atores pertinentes ao universo futebolístico, inclusive os torcedores, "passaram a desempenhar e ocupar papéis específicos no 'negócio do futebol". 45 Portanto,

é diante desta aquarela que se estabelecem as Alianças entre os grupos organizados de torcedores, como estratégia de defesa e resposta diante da espetacularização promovida pelos veículos de comunicação - em torno dos episódios violentos -, onde em busca de soluções ao "mal do futebol brasileiro" imputou sistematicamente aos grupos de torcedores a quase totalidade pela responsabilidade da violência registrada no futebol nacional [...] como consequência, interpretados como outsiders, e estigmatizados pelo discurso construído pelas classes hegemônicas do futebol nacional, os grupos organizados de torcedores necessitaram de novas relações que lhes rendessem recursos, visibilidade e crescimento, possibilitando, desta forma, aproximações entre grupos de cidades e estados diferentes do país. ${ }^{46}$

Habitualmente, em dias de jogos, torcedores do time adversário não circulam pelo território e possuem um setor de entrada específica no estádio, onde há fixada escolta policial, justamente para promover a segurança e prevenir possíveis enfrentamentos. Naquela tarde foi percebida uma configuração de espaço-tempo vivido de atores em uma situação peculiar, promovida pela aliança estabelecida entre torcedores gremistas e vascaínos. Através deste pacto entre as torcidas organizadas, os visitantes agregam status de aliadas no território, através de um valor simbólico de trocas. A parceria estabelecida proporciona aos gremistas as mesmas permissões, quando o jogo é no território adversário, o que pode ser entendido na conversa com os torcedores do Vasco:

Quando pergunto se eles vêm aos jogos com frequência, é garantido que a todos os jogos marcam presença. Chegam sempre cedo para confraternizar, pois fazem um almoço que acontece na Torcida Jovem ou na Geral do Grêmio. Comentam que a aliança permite que eles circulem pelo território do Grêmio, assim como acontece, de forma recíproca quando os torcedores gremistas também vão aos jogos na casa do Vasco. ${ }^{47}$

Conforme a participação dos clubes que competem regularmente nas principais competições do calendário nacional foi se ampliando, os contatos entre os grupos torcedores de estados diferentes "passaram a ser mais corriqueiros e

\footnotetext{
45 SOUZA. Fazer alianças, uma escolha determinante entre o protagonismo e a invisibilidade dos grupos organizados de torcedores de futebol no Brasil, 2016, p. 20.

46 SOUZA. Fazer alianças, uma escolha determinante entre o protagonismo e a invisibilidade dos grupos organizados de torcedores de futebol no Brasil, 2016, p. 21-2.

47 DIÁRIO DE CAMPO V, 11 nov. 2018.
} 
intensos. Essa situação acabou aumentando a necessidade de assistência durante as viagens e permanências em outras cidades". ${ }^{48}$

Portanto, sinalizamos que o território investigado é tramado na teia da multiterritorialidade (Fig. 2), pois se trata da experiência integrada do espaço, na forma de territórios-rede. São gremistas, torcedores aliados, guardadores, catadores, comerciantes e demais sujeitos que se relacionam e compõe o território das imediações da Arena do Grêmio. Ademais, os dias de jogos no estádio compõem as vidas de moradores não somente de suas imediações, mas também de bairros próximos, de outras zonas de Porto Alegre e de outras cidades e estados, já que a multiterritorialidade não se trata de acessar diferentes territórios, mas de, por meio da experiência espacial integrada de dominação, fazer parte deles. ${ }^{49}$ Assim, falar da totalidade das relações territoriais das imediações da Arena é falar da indissociabilidade entre espaço, tempo e vidas.

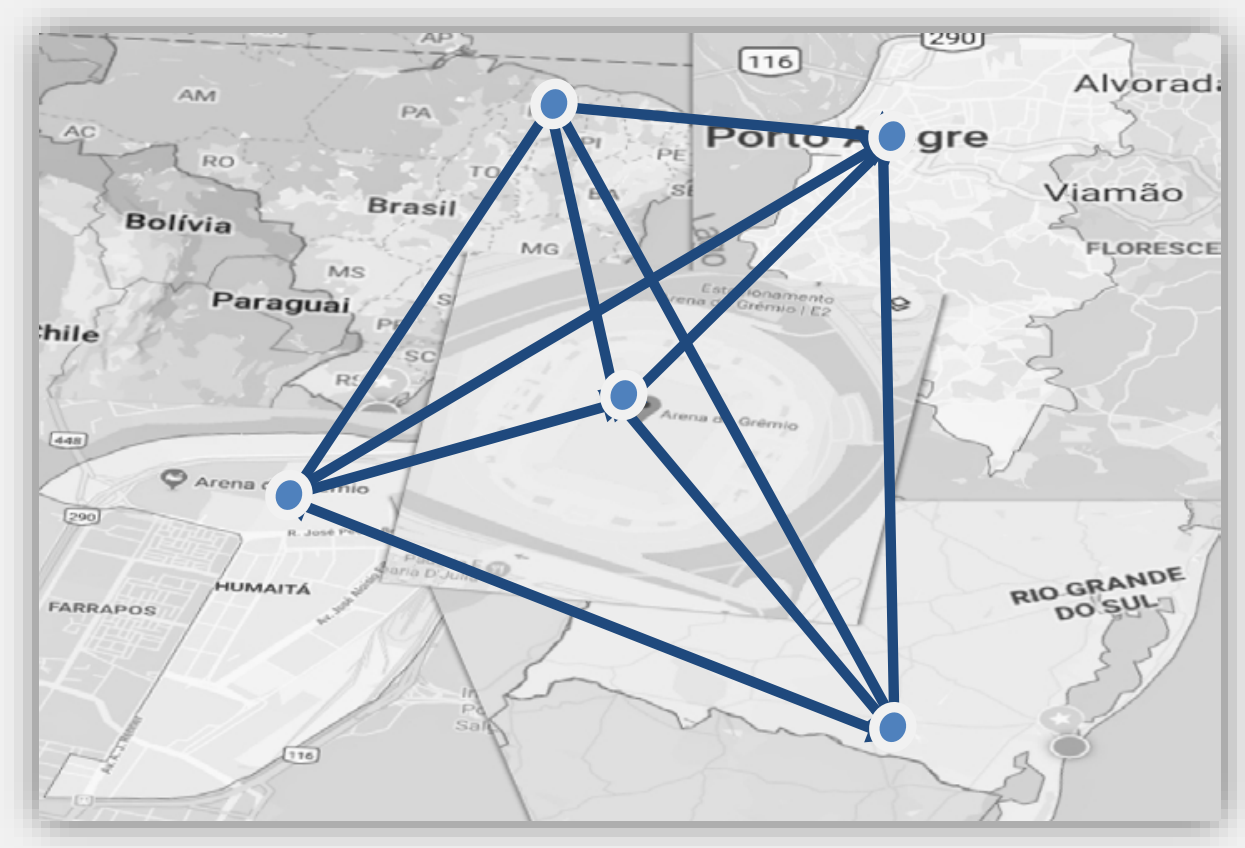

Fig. 2: Composição multiterritorial.

${ }^{48}$ SOUZA. Fazer alianças, uma escolha determinante entre o protagonismo e a invisibilidade dos grupos organizados de torcedores de futebol no Brasil, 2016, p.22.

${ }^{49}$ HAESBAERT. O mito da desterritorialização, 2010. 


\section{CONSIDERAÇõES}

No contexto investigado, consideramos que a apropriação do território das imediações da Arena do Grêmio se constitui como lugar de festividade e de trabalho. Celebrar e trabalhar são formas interligadas de fazer a festa acontecer, através da sociabilidade e relações comerciais. É o espaço-tempo vivido do encontro entre sujeitos, entre os pares e com torcidas aliadas. É o lado de fora do estádio, mas é o lado de dentro da festa das manifestações torcedoras gremistas.

Quanto à composição na vida de moradores das imediações da Arena, parte dos lares da avenida Padre Leopoldo Brentano interage com a transformação ocorrente, principalmente no que tange às relações comerciais. No entanto, a insatisfação também se faz presente com toda transformação decorrente do dia de jogo. Isso considerando quem não interage de forma lucrativa com a festa e também não torce pelo Grêmio. Logo, ser morador das imediações da Arena em dias de jogos pode significar a dádiva para alguns e o incômodo para outros.

Faz parte da apropriação do território consumir e as atividades de geração de renda, na inter-relação consumo/comércio, são contempladas também por moradores de bairros próximos ao estádio e de outras localidades. A composição dos dias de jogos na Arena se estende para além de suas imediações, configurando a cidade, que se desenha de forma peculiar, nesses dias. Mesmo que o dia de jogo não faça parte da vida diária de Porto Alegre, ele faz parte da estrutura, da organização de vidas de moradores da capital e de outras localidades que, na celebração do dia de jogo na Arena, estabelecem suas sociabilidades e relações de trabalho.

Consideramos, assim, que o território dos dias de jogos na Arena é lugar inerente às vidas de moradores das imediações do estádio, dos bairros próximos, de outras localidades de Porto Alegre, de outras cidades e de outros estados, que se compõem a partir da celebração do dia de jogo. Portanto, o território é constituído nas nuances de suas ambiguidades, na multiplicidade de inter-relações, significados e pertencimentos que são pertinentes às relações de apropriação e dominação do espaço, tramadas nas redes da multiterritorialidade. 


\section{REFERÊNCIAS}

ANGROSINO, Michael. Etnografia e observação participante. Porto Alegre: Artmed, 2009.

BAUMAN, Zygmunt; MAY, Tim. Aprendendo a pensar com a Sociologia; tradução Alexandre Werneck. Rio de Janeiro: Zahar, 2010.

BIANCH, Greison. Agentes e práticas da organização capitalista do espaço o espetáculo do bairro Humaitá. Monografia. Universidade Federal do Rio Grande do Sul, Porto Alegre, 2012.

DAMO, Arlei Sander. Senso de jogo. Esporte e Sociedade, Rio de Janeiro, n. 1, p. 1-43, 2006.

DAMO, Arlei Sander. Futebol e identidade social: uma leitura antropológica das rivalidades entre torcedores e clubes. Porto Alegre, Ed. Universidade/ UFRGS, 2002.

DAMO, Arlei Sander. Do dom à profissão: a formação de futebolistas no Brasil e na França. São Paulo: Aderaldo \& Rothschild: Anpocs, 2007.

ELIAS, Norbert. O processo civilizador: uma história dos costumes. Rio de Janeiro: Jorge Zahar, 1994.

GONÇALVES, Marcelino Andrade. O trabalho no lixo. Tese de Doutorado em Geografia. Presidente Prudente: FCT/UNESP, 2006.

GOMES, Edlaine de Campos; MENEZES, Rachel Aisengart. Etnografias possíveis: "estar" ou "ser" de dentro. Ponto Urbe, Revista do núcleo de antropologia urbana da USP, 2008.

HAESBAERT, Rogério. O mito da desterritorialização: do "fim dos territórios" à multiterritorialidade. Rio de Janeiro: Bertrand Brasil, 2010.

HAESBAERT, Rogério. Território e multiterritorialidade: um debate. Geographia, ano IX, n. 17, 2007.

MARTINS, Daiane Grillo; KNUTH, Alan Goularte. Manifestações torcedoras e território: configurações das imediações da Arena do Grêmio, Revista Movimento, Porto Alegre, v. 26, 2020.

MARTINS, Daniella Paula. O Humaitá de ontem, de hoje e de amanhã. Dissertação, Universidade Federal do Rio Grande do Sul. Porto Alegre, 2010.

MARTINS, Heloísa Helena de Souza. Metodologia qualitativa de pesquisa. Educação e Pesquisa, São Paulo, v. 30, n. 2, p. 289-300, 2004.

MASCARENHAS, Gilmar. Construindo a pátria de chuteiras: elementos para uma geografia da difusão do futebol no Brasil. In: SCHÄFFER, Neiva et al. (Orgs). Ensinar e Aprender Geografia. Porto Alegre: AGB, 1998, p. 93-103.

MASCARENHAS, Gilmar. A Geografia e os esportes: uma pequena agenda e amplos horizontes. Conexões - Revista da Faculdade de Educação Física da UNICAMP, v. 1, n. 2, p. 47-61, 1999. 
MASCARENHAS, Gilmar. À Geografia dos esportes: uma introdução. Scripta Nova - Revista Electrónica de Geografía y Ciencias Sociales. Universidad de Barcelona, n. 35, 1999b.

OLIVEIRA, Roberto Cardoso de. O trabalho do antropólogo. Brasília: Paralelo 15; São Paulo: Editora Unesp, 2006.

RODRIGUES, Francisco Carvalho dos Santos. Amizade, trago e alento - A Torcida Geral do Grêmio (2001-2011) da rebeldia à institucionalização: mudanças na relação entre torcedores e clubes no campo esportivo brasileiro. 142 p. Dissertação. Universidade Federal Fluminense, Niterói, 2012.

SANTOS, Milton. Metamorfoses do espaço habitado, fundamentos teórico e metodológico da geografia. Hucitec. São Paulo, 1988.

SILVA, Helio. A situação etnográfica: andar e ver. Horizontes Antropológicos, Porto Alegre, ano 15, n. 32, p. 171-188, 2009.

SILVA, Silvio Ricardo da. A construção social da paixão no futebol: o caso do Vasco da Gama. In: DAOLIO, Jocimar. (Org). Futebol, cultura e sociedade. Campinas, SP: autores associados, 2005.

SOUZA, Eduardo Araripe Pacheco de. Fazer alianças, uma escolha determinante entre $o$ protagonismo e a invisibilidade dos grupos organizados de torcedores de futebol no Brasil. Tese. Programa de pósgraduação em Antropologia da UFPE, Recife, 2016.

TOLEDO. Luiz Henrique de. Quase lá: a Copa do Mundo no Itaquerão e os impactos de um megaevento na socialidade torcedora. Horizontes Antropológicos, Porto Alegre, ano 19, n. 40, p. 119-148, 2013.

Recebido para publicação em: 06 jun. 2020. Aprovado em: 07 out. 2020. 